\title{
Expression of public idiotypes in patients with Lyme arthritis
}

\author{
J S Axford, R A Watts, A A Long, D A Isenberg, A C Steere
}

Academic

Rheumatology Unit, Division of Immunology, St George's Hospital Medical School, London,

United Kingdom

J S Axford

Department of

Rheumatology

Research, University

College and Middlesex

School of Medicine,

University of London,

United Kingdom

R A Watts

D A Isenberg

Divisions of

Rheumatology/

Immunology, and

Allergy, New England

Medical Center, Tufts

University School of

Medicine, Boston,

Massachusetts, USA

A A Long

A C Steere

Correspondence to

Dr J S Axford,

Academic Rheumatology

Imit, Division

Immunology,

Molecular Sciences

St George's Hospital Medical

St George's Hospital Medical

London SW 17 ORE

United Kingdom.

Accepted for publication

29 October 1992

\begin{abstract}
Objective Joints are often affected in Lyme disease and in some instances this may be due to immune autoreactivity. To characterise further the immune response in this disease investigations were carried out to determine the expression of three public idiotypes on serum immunoglobulins in patients with Lyme disease during the development of varying degrees of arthritis.
\end{abstract}

Methods The expression of idiotypes (Ids) 16/6, BEG2, and PR4, first identified on monoclonal antibodies to DNA, was determined by an enzyme linked immunosorbent assay (ELISA) in serial blood samples from 12 patients with Lyme disease over a mean period of six years during the development of a variety of arthritic symptoms, and in serum samples from healthy control subjects and control subjects with systemic lupus erythematosus.

Results Expression of serum IgM or IgG public Ids $16 / 6$ and BEG2 was significantly increased in patients with Lyme disease. IgA Id 16/6 expression, in contrast, was significantly increased only during episodes of arthritis and was also related to its severity. IgM and IgG Id 16/6 expression was related to their respective total immunoglobulin concentration and, in the case of IgM, to the level of IgM antibodies to Borrelia burgdorferi, whereas similar findings were not apparent with IgA antibodies. This may indicate that the $\operatorname{IgA}$ response is related to the pathogenesis of arthritis, especially as total IgA and IgA Id 16/6 levels were found to increase over the duration of disease. Sequential analysis of antibodies also showed restriction in the expression of Id $16 / 6$ as it was never found on all immunoglobulin isotypes at the same time, and Id PR4 was never expressed. Ids $16 / 6$ and BEG2 expression, however, may be associated as seven patients expressed these idiotypes simultaneously.

Conclusions These data indicate the use of public idiotypes in the immune response against $B$ burgdorferi, which may be restricted in terms of idiotype class and isotype expression, and a possible association between IgA antibodies bearing Id $16 / 6$ with arthritis.

(Ann Rheum Dis 1993; 52: 199-205)
Lyme disease is a multisystem disorder caused by a tick transmitted Gram negative spirochaete Borrelia burgdorferi. The initial manifestations of the disease are the characteristic skin lesion, erythema migrans, and flu-like or meningitis-like symptoms, which may be followed by cardiac, neurological, or joint manifestations. ${ }^{1}$ Joint symptoms often begin with migratory arthralgia followed months later by brief attacks of oligoarthritis. In about $10 \%$ of patients with joint disease chronic arthritis develops during the second or third year of illness, sometimes leading to erosion of the cartilage and bone. The synovial lesion in Lyme arthritis is histologically similar to that found in rheumatoid arthritis, and chronic Lyme arthritis is thought to have an autoimmune basis because of the association with the HLA class II DR4 and DR2 genes. The cellular and humoral immune responses in Lyme disease develop gradually over a period of months to an increasing array of spirochaetal polypeptides, ${ }^{2}$ which may be associated with the production of a population of anticardiolipin (aCL) antibodies, possibly as a direct response to $B$ burgdorferi phospholipid antigen. ${ }^{3}$ Interestingly, in most patients Lyme arthritis can be successfully treated with antibiotics, but a small percentage of patients, primarily those with HLA-DR4, do not respond to this treatment.

Idiotypes (Ids) are variable region structures on immunoglobulins which are located at or adjacent to the binding site. Anti-idiotypic antibodies can be used to identify public (cross reactive) and private idiotypic determinants, and their analysis allows the study of the genetic relation between antibodies. Ids $16 / 6,{ }^{4}$ PR $4,{ }^{5}$ and $\mathrm{BEG} 2{ }^{6}$ are public Ids that were first identified on human monoclonal antibodies to DNA derived from the peripheral blood lymphocytes of patients with haemolytic anaemia (16/6) and leprosy (PR4), and from normal fetal hepatocytes (BEG2). They have subsequently been found to be expressed on serum and tissue bound immunoglobulins of patients with a variety of autoimmune rheumatic diseases. Id $16 / 6$ has also been identified on antibodies to $\mathrm{K} 30$ in patients with klebsiella infections and on the serum immunoglobulins of $60 \%$ of patients with Mycobacterium tuberculosis infection. It has been shown by mRNA sequencing that the heavy chain of the monoclonal antibody bearing 16/6 is identical to that of the germline gene $V_{H} 26{ }^{7}$ It is thought that Id $16 / 6$ is on the heavy chain. 
Thus the public expression of Id 16/6 may well be the result of a conserved germline $\mathrm{V}$ gene, primarily involved in antibody production against environmental pathogens. It may also be associated with pathological autoantibodies, however, as it has been detected on immunoglobulins deposited in the kidneys of patients with systemic lupus erythematosus (SLE). ${ }^{8}$

We report here the longitudinal expression of these three public idiotypes in serial serum samples from 12 patients with erythema migrans followed by brief or prolonged episodes of Lyme arthritis.

\section{Patients and methods}

PATIENTS AND CONTROL SUBJECTS

We studied 68 serial serum samples in 12 patients from New England, USA, who had erythema migrans followed by arthralgia or one brief attack of arthritis lasting no longer than six weeks (brief arthritis, four subjects), or by intermittent or chronic arthritis for three to six years (prolonged arthritis, eight subjects). Five patients had neurological symptoms early in their illness (four meningitis, one Bell's palsy). The 12 patients had a mean age of 45 years (range 9-71 years), 10 were men and two women. They were followed up for a mean duration of six years (range one to nine). Lyme disease was initially diagnosed in these patients by the presence of erythema migrans before the causative agent or efficacy of antibiotic treatment was known. It was later shown that all 12 patients had increased IgG antibody titres to $B$ burgdorferi. Patients were scored for the severity of joint swelling as follows: $0=$ no swelling, $1=$ mild, $2=$ moderate, and $3=$ severe swelling.

For the investigation of Ids $16 / 6$ and PR4, serum samples from 23 healthy subjects with no personal or family history of autoimmune disease were used as healthy controls and serum samples from 15 patients with active SLE were used as disease controls. In the Id BEG2 assay a different panel of serum samples from 20 healthy subjects was used, again with no personal or family history of autoimmune disease.

IDIOTYPE ASSAYS

Antibodies against idiotypes 16/6, BEG2, and PR4 were prepared in rabbits, extensively adsorbed against human $\mathrm{IgG/IgM}$, and used at a concentration at which there is negligible background binding of irrelevant rabbit polyclonal antibody, as detailed elsewhere. ${ }^{4-6}$ The identification of Ids 16/6 and PR4 on serum immunoglobulins (Ig) was carried out by an enzyme linked immunosorbent assay (ELISA) using the rabbit polyclonal antiidiotype reagent. Negative and positive control serum samples were used on each plate together with the test serum samples. Serum dilution and capture antibody concentration were chosen to ensure saturation by serum immunoglobulins. The following techniques were used:
Immulon 1 (Dynatech) microtitre plates were coated with goat antihuman IgG Fc (Sigma Chemicals, $1 \mu \mathrm{g} / \mathrm{ml}$ in borate buffer), which had been previously adsorbed against normal rabbit serum for 18 hours at $4^{\circ} \mathrm{C}$. Immulon 2 and Nunc plates were similarly coated and incubated with goat antihuman IgM (Capell, $1 \mu \mathrm{g} / \mathrm{ml}$ in borate buffer) and goat antihuman IgA (Sigma Chemicals, 0.5 $\mu \mathrm{g} / \mathrm{ml}$ in borate buffer) respectively. Each well was washed and then blocked with phosphate buffered saline (PBS)-3\% bovine serum albumin (BSA) and then washed five times with PBS-0.05\% Tween (PBS-T). A $75 \mu \mathrm{l}$ volume of serum, diluted $1: 200$ in PBS, 3\% goat serum, $1 \% \mathrm{BSA}$, and $0.05 \%$ Tween (Sigma Chemicals), was added in duplicate to the wells and incubated for two hours at $37^{\circ} \mathrm{C}$. Each plate was washed five times with PBS-T. Aliquots $(75 \mu \mathrm{l})$ of either rabbit anti-16/6 $(1 / 20000)$ or rabbit anti-PR4 (1/2000), diluted in $3 \%$ goat serum, $1 \%$ BSA, and PBS$\mathrm{T}$, were then added to the wells and incubated for two hours at $37^{\circ} \mathrm{C}$. Each plate was again washed five times with PBS-T before incubating overnight with $75 \mu \mathrm{l}$ aliquots of goat $\mathrm{F}\left(\mathrm{ab}^{\prime}\right)_{2}$ antirabbit Ig alkaline phosphatase conjugate (Sigma Chemicals), which had previously been adsorbed against human serum and diluted in PBS-3\% goat serum, $1 \%$ BSA, and $0.05 \%$ Tween. Each plate was developed using Sigma 104 alkaline phosphatase substrate after washing five times with PBS-T, and absorbances were subsequently measured at $405 \mathrm{~nm}$ after six hours at room temperature. Reference to healthy control serum samples on each ELISA plate was made to enable accurate comparison of absorbance readings obtained from different experiments and the presence of Ids $16 / 6$ and PR4 was expressed as ratios of the average absorbance obtained for the duplicate Lyme disease and SLE samples against the average absorbance obtained from the healthy subjects on each plate.

A capture ELISA was used to detect the Id BEG2 $(\beta)$ on Ig in human serum samples. ${ }^{6}$ Id BEG2 levels were expressed in arbitrary units (100 BEG2 units $=100 \%$ binding of standard serum) and this assay does not distinguish between IgG or IgM isotypes.

Quantification of the level of expression was made by comparison to the number of standard deviations (SD) greater than the healthy control mean value. Antibody levels are reported as positive if levels were greater than or equal to two SD above the mean.

\section{MEASUREMENT OF SERUM ANTIBODIES TO} $B$ burgdorferi AND TOTAL IMMUNOGLOBULIN LEVELS

Antibodies to $B$ burgdorferi antigen were measured by ELISA as described previously. ${ }^{9}$ Briefly, IgM and IgA antibodies to $B$ burgdorfer $i$ were detected using an immunoglobulin capture technique followed by exposure of the immunoglobulin to $B$ burgdorferi antigen and then detection of antibodies specific to $B$ burgdorferi with a rabbit antibody against the 
borrelia antigen. IgG antibodies to $B$ burgdorferi were detected by their ability to directly bind sonicated $B$ burgdorferi antigen. Antibody to $B$ burgdorferi values are expressed either as direct absorbances or as titres, or, for IgA, as an absorbance ratio of a positive standard. IgM titres $\geqslant 1 / 200$, IgG titres $\geqslant 1 / 400$, and IgA ratios $\geqslant 2.0$ were considered increased. Total immunoglobulins were measured by standard nephelometry techniques (Beckman assay immunochemistry system). Normal ranges were $\operatorname{IgM} 0 \cdot 45-1 \cdot 50, \operatorname{IgG} 8 \cdot 0-15 \cdot 0$, and $\operatorname{IgA}$ $0 \cdot 98-3 \cdot 25 \mathrm{~g} / 1$.

\section{MEASUREMENT OF ANTICARDIOLIPIN} ANTIBODIES

Anticardiolipin antibodies were detected by ELISA as reported previously. ${ }^{10}$ Essentially, serum samples were diluted $1 / 50$ in PBS-10\% adult bovine serum and assayed in triplicate for IgM aCL and IgG aCL antibodies. Each plate included two positive and eight negative control samples and positive results were those with absorbances above the mean +2 SD of the negative controls.

MEASUREMENT OF ANTIBODIES TO $B$ burgdorfer $i$ EXPRESSING ID $16 / 6$

To determine whether serum antibodies with $B$ burgdorferi antigen binding specificity from patients with Lyme arthritis expressed Id 16/6, a modification of the Id 16/6 ELISA assay was used. Serum samples from three patients with prolonged arthritis who expressed Id $16 / 6$ on their total serum Ig were selected, together with serum samples from one patient with active SLE and from one healthy subject. Nunc plates were coated with sonicated $B$ burgdorfer $i$ (strain B31, $5 \mu \mathrm{g} / \mathrm{ml}$ in carbonate buffer), antibodies captured from the serum samples were doubly diluted four times $(1 / 300-1 / 2400)$ and Id $16 / 6$ expression determined as described previously.

\section{STATISTICS}

Statistics used in analysing the data were Student's $t$ test, the Pearson coefficient of product-moment correlation, the standard error of the mean (SEM), and the standard normal deviant test was used to compare regression analyses.

\section{Results}

TOTAL SERUM ANTIBODIES, ANTIBODIES TO

$B$ burgdorferi, AND ANTICARDIOLIPIN ANTIBODIES

In patients with prolonged arthritis, the mean total IgA concentration decreased over the first two years of illness $(r=-0.996 ; p<0.03)$, but increased over the subsequent four years $(\mathrm{r}=0.947 ; \mathrm{p}<0.02)$. The reverse was found with levels of IgA antibodies to $B$ burgdorfer and a significant reduction in levels (mean(SEM)) was observed between years two $(7 \cdot 05(1 \cdot 84))$ and six $(4 \cdot 02(0 \cdot 75))$ of follow up $(\mathrm{p}<0.03)$. In contrast, the mean total serum IgG and $\operatorname{IgM}$ levels decreased over the period of investigation (IgG r $=-0.939, \mathrm{p}=0.002 ; \mathrm{IgM}$ $\mathrm{r}=-0.831, \mathrm{p}<0.02)$, and though a slight increase in levels of IgG antibodies to $B$ burgdorferi was noted over the initial two years, levels of $\operatorname{IgG}$ and $\operatorname{IgM}$ antibodies to $B$ burgdorferi also decreased (IgG $\mathrm{r}=-0.830$, $\mathrm{p}<0.05 ; \operatorname{IgM} \mathrm{r}=-0.526, \mathrm{p}<0.05)$.

In patients with brief arthritis, the mean total IgM levels decreased over the period of investigation $(r=-0.987 ; \mathrm{p}<0.05)$. Total IgG and $A$ values were always within normal limits and levels of antibodies to $B$ burgdorferi of all isotypes were increased and did not fluctuate over the period of investigation.

Anticardiolipin antibody levels were increased on one occasion in two asymptomatic patients with Lyme disease with no previous history of neurological disease - one with brief arthritis (IgG antibody greater than three SD of the negative control mean) and the other with prolonged arthritis (IgM antibody greater than five SD of the negative control mean).

\section{ID 16/6 EXPRESSION ON TOTAL SERUM} ANTIBODIES

The table gives the total mean (range) (SEM) immunoglobulin (Ig) absorbance readings after six hours from all experiments .

Levels of IgM and IgG antibodies from patients with Lyme disease and SLE were significantly increased compared with those from healthy control subjects (Lyme disease $\operatorname{IgM} p<0.01, \operatorname{IgG} p<0.02 ;$ SLE IgM $p<0.05$, IgG $\mathrm{p}<0.001$ ).

Expressing the data as a ratio of the absorbance value obtained from healthy subjects, the levels of IgM and IgG isotypes

Total mean (range) (SEM) immunoglobulin absorbance readings after six hours from experiments conducted to detect idiotype (Id) expression on total serum antibodies

\begin{tabular}{|c|c|c|c|c|}
\hline Idiotype & Isotype & Patients with Lyme disease & $\begin{array}{l}\text { Patients with systemic } \\
\text { lupus erythematosus }\end{array}$ & Healthy subjects \\
\hline Id $16 / 6$ & $\begin{array}{l}\text { IgM } \\
\text { IgG } \\
\text { IgA }\end{array}$ & $\begin{array}{c}162 \cdot 8(0-722)(15 \cdot 6)^{\star} \\
44 \cdot 8(0-136)(2 \cdot 9) \dagger \\
19 \cdot 3(3-47)(1 \cdot 2)\end{array}$ & $\begin{array}{c}210 \cdot 2(23-1200)(74 \cdot 0) \ddagger \\
67 \cdot 3(6-190)(18 \cdot 9) \rrbracket \\
19 \cdot 1(2-44)(3 \cdot 0)\end{array}$ & $\begin{array}{l}92 \cdot 2(0-325)(16 \cdot 6) \\
33 \cdot 9(0-63)(3 \cdot 4) \\
14 \cdot 9(0-45)(2 \cdot 9)\end{array}$ \\
\hline Id BEG2 & $\mathrm{IgG} / \mathrm{M}$ & $243 \cdot 9(31-611)(17 \cdot 4)$ & ND & $229 \cdot 6(25-398)(17 \cdot 6)$ \\
\hline Id PR4 & $\begin{array}{l}\text { IgM } \\
\text { IgG } \\
\text { IgA }\end{array}$ & $\begin{array}{l}333 \cdot 5(44-1500)(16 \cdot 8) \\
143 \cdot 1(13-1100)(9 \cdot 8) \\
109 \cdot 8(2-305)(6 \cdot 8)\end{array}$ & $\begin{array}{l}396 \cdot 0(17-1500)(59 \cdot 0) \\
140 \cdot 0(57-474)(13 \cdot 9) \\
245 \cdot 2(21-1000)(42 \cdot 1) \dagger\end{array}$ & $\begin{array}{l}302 \cdot 8(79-704)(26 \cdot 6) \\
131 \cdot 6(17-263)(10 \cdot 0) \\
146 \cdot 1(12-314)(16 \cdot 1)\end{array}$ \\
\hline
\end{tabular}




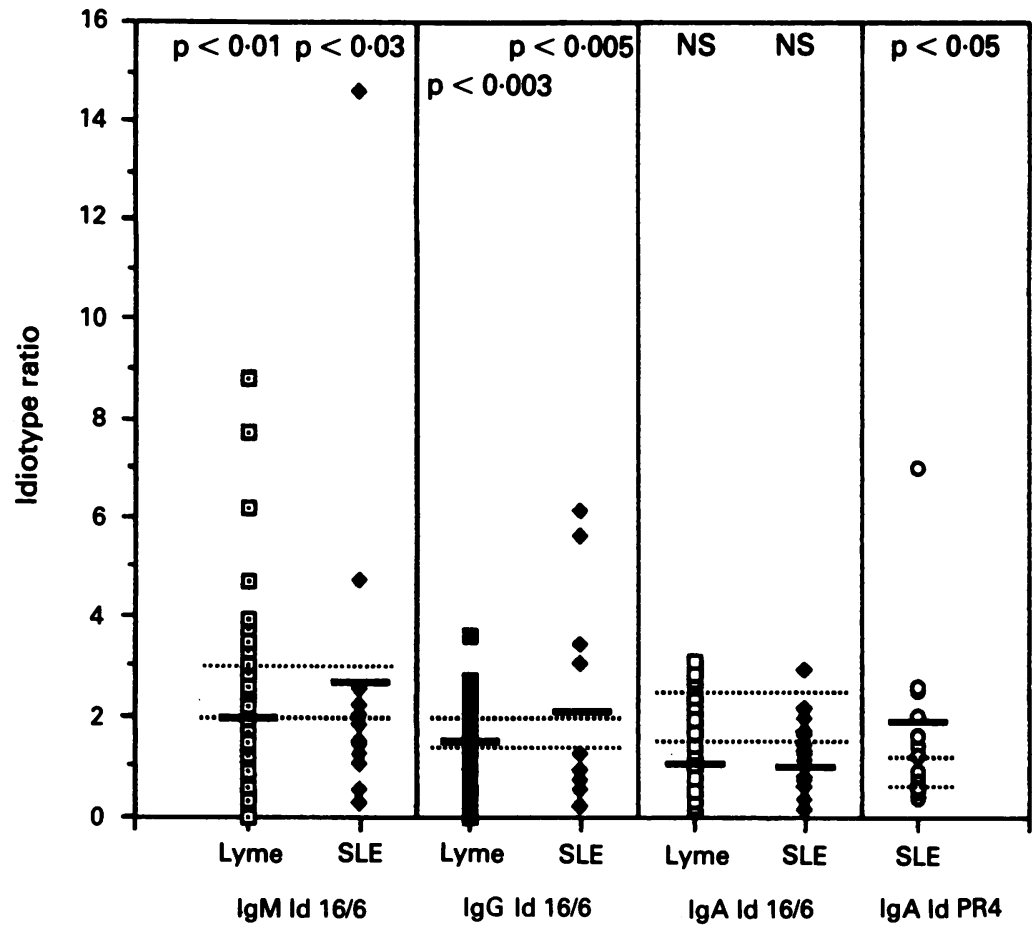

Figure 1 Expression of idiotypes (Id) 16/6 and PR4 on serum immunoglobulins in Lyme disease $(n=68)$ and $S L E(n=15)$. Idiotype ratio is the mean absorbance ratio of test/control serum samples. The solid bars indicate mean values, the broken bars indicate standard deviations above the control mean $(\times 2=u p p e r$ bar, $\times 1=$ lower bar), and the dots represent each serum sample tested. A significant increase in IgM and IgG Id 16/6 expression was found in patients with Lyme disease, but IgA Id 16/6 expression was only increased in those patients developing Lyme arthritis.

(mean(SEM)) bearing Id $16 / 6$ were significantly increased in patients with erythema migrans followed by brief or prolonged episodes of Lyme arthritis (IgM $2 \cdot 0(0 \cdot 2), \mathrm{p}<0 \cdot 01$; IgG $1 \cdot 3(0 \cdot 1), \mathrm{p}<0 \cdot 003)$ compared with healthy control subjects, but the mean level of IgA immunoglobulins bearing this idiotype was not increased (fig 1). Positive levels of IgM and IgG Id $16 / 6$ antibodies were detected in $5 / 12$ and $6 / 12$ patients respectively, primarily during the first several years of illness. In contrast, significantly increased levels of IgA Id 16/6 antibodies $(1.4(0.2) ; \mathrm{p}=0.05)$ were found only during the period of joint disease when compared with healthy control subjects, and positive levels were detected in three of eight patients who developed prolonged arthritis. In the 15 control patients with SLE, as in the patients with Lyme disease, the mean level of IgM and IgG Id $16 / 6$ antibodies was significantly increased (IgM 2.6(0.9), p<0.03; IgG $2 \cdot 2(0 \cdot 7), \mathrm{p}<0 \cdot 005)$. These patients did not have increased Id $16 / 6$ expression on IgA antibodies, however.

In the eight patients with erythema migrans followed by prolonged arthritis, IgA Id 16/6 expression increased significantly during the first (from $1 \cdot 1(0 \cdot 1)$ to $1 \cdot 7(0 \cdot 3) ; \mathrm{p}<0.05)$ and third (from $1 \cdot 2(0.3)$ to $1 \cdot 8(0.2) ; \mathrm{p}<0.05$ ) years of illness and remained high thereafter (fig 2); levels of IgG Id 16/6 remained high throughout the initial years of illness; and expression of IgM Id 16/6 was highest during the first year of illness and generally decreased in each subsequent year $(r=-0.792 ; p<0.05)$. In contrast, in the four patients with erythema migrans followed by brief episodes of arthritis, Id 16/6 expression on all isotypes was highest when the skin lesion was present and decreased thereafter. No patient had Id $16 / 6$ expression on all isotypes simultaneously, and only one patient with prolonged arthritis had increased expression of this idiotype on each isotype at different times.

IgA Id 16/6 expression correlated directly with the severity of arthritis $(r=0.258 ; p<0.02)$, but not with the erythrocyte sedimentation rate (ESR); IgM and IgG Id $16 / 6$ expression correlated with neither the severity of arthritis nor the ESR. The levels of IgM and IgG Id $16 / 6$ correlated directly with their respective total immunoglobulin concentrations (IgM $\mathrm{r}=0.538$; IgG $\mathrm{r}=0.308$; in both instances $\mathrm{p}<0.001$ ), whereas the levels of IgA Id $16 / 6$ did not. Similarly, IgM Id 16/6 expression showed a positive correlation with levels of IgM antibodies to $B$ burgdorferi $(\mathrm{r}=0.264 ; \mathrm{p}<0.025)$, but the other antibody isotypes did not. There was a significant difference $(p<0.05)$ between the overall positive correlation of IgA Id 16/6 expression $(r=0.439 ; p=N S)$ and the negative correlation of IgM Id 16/6 expression with disease duration.

\section{ID $16 / 6$ EXPRESSION ON ANTIBODIES TO} $B$ burgdorferi

The total mean (SEM) absorbance readings for the three patients with Lyme disease were as follows: $1 / 300,338 \cdot 3(84 \cdot 8) ; 1 / 600$, $253.3(103.6) ; 1 / 1200,173 \cdot 3(66.9)$, and $1 / 2400,135 \cdot 0(60 \cdot 7)$. Id $16 / 6$ expression was not detected when serum samples, from the patient with SLE nor from the healthy subject were used.

ID BEG2 EXPRESSION ON TOTAL SERUM ANTIBODIES

The table gives the total mean (range) (SEM) absorbance readings from all experiments.

When the data were expressed as the percentage binding relative to a standard serum sample, patients with Lyme disease had significantly increased levels of expression of IgM and IgG BEG2 when compared with healthy subjects (37(5) $v 20(2) ; \mathrm{p}<0.02)$. Positive levels of IgM and IgG BEG2 expression were detected in 6/12 patients, which included some with brief or prolonged arthritis, and this was predominantly early in the illness. There was no association betwen Id BEG2 expression and arthritis score, ESR, total immunoglobulin, or levels of antibodies to $B$ burgdorferi.

\section{ID PR4 EXPRESSION ON TOTAL SERUM} ANTIBODIES

The table gives the total mean (range) (SEM) absorbance readings for all experiments.

The IgA absorbance readings for subjects with SLE were significantly increased $(p<0.02)$ compared with healthy control subjects.

When the data were expressed as a ratio of the absorbance value obtained from healthy subjects, Id PR4 expression was again not significantly different in the patients with Lyme disease compared with the healthy control 
Brief arthritis
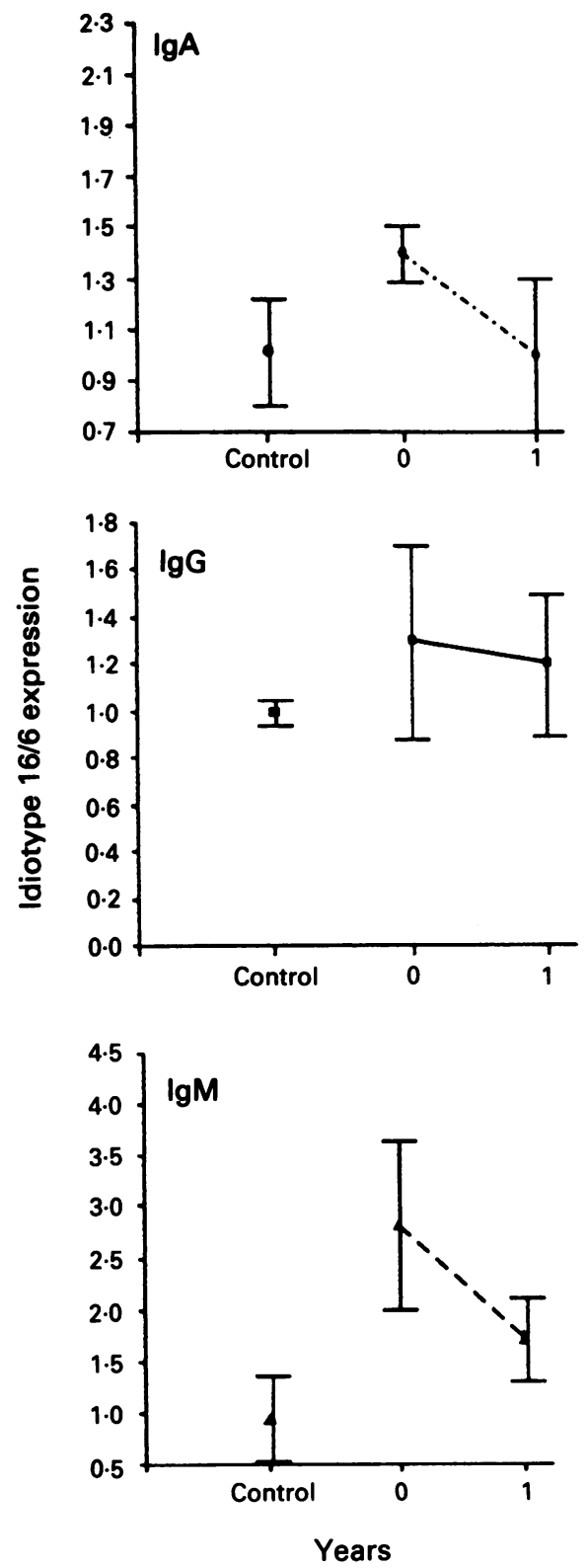

Prolonged arthritis
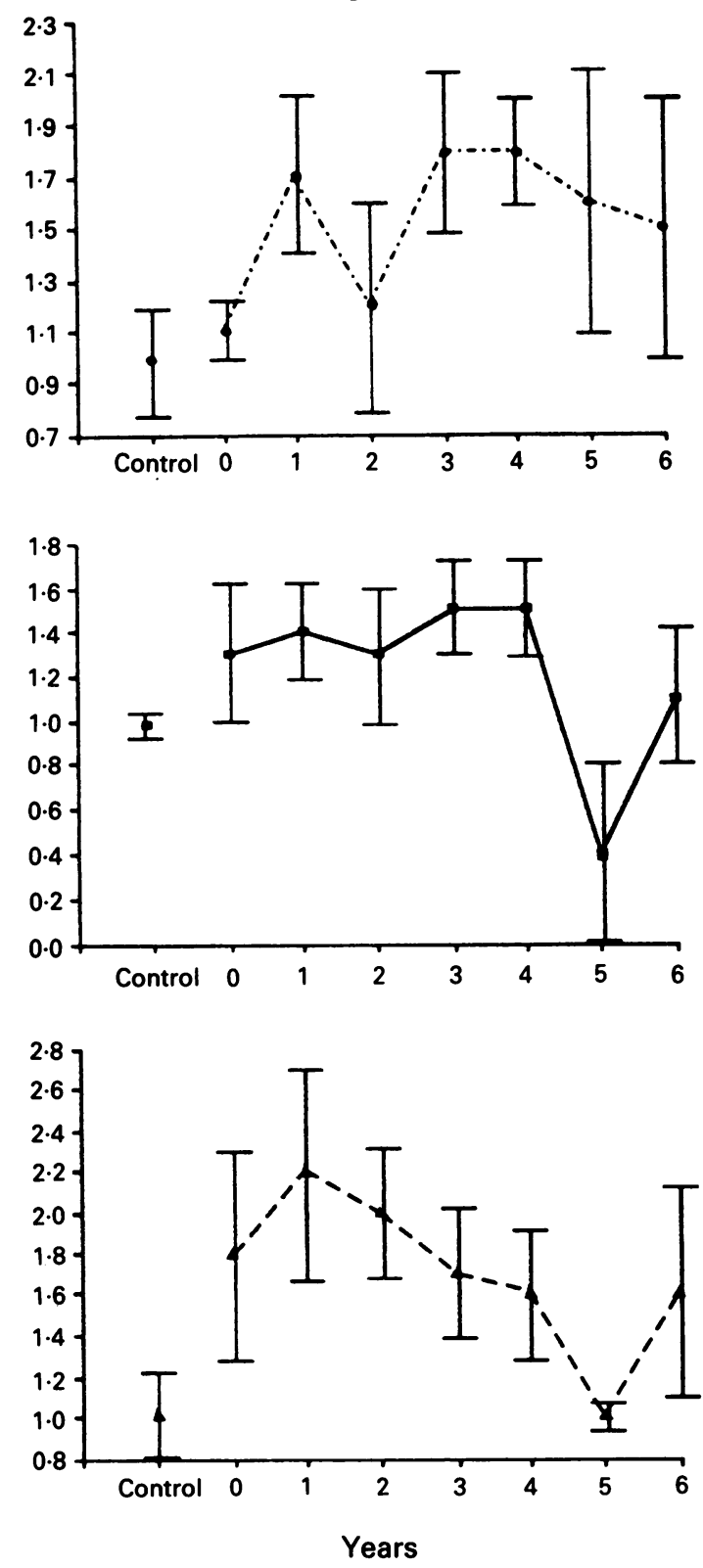

Figure 2 Serum immunoglobulin idiotype (Id) 16/6 expression (mean ratio (SEM)), in patients with Lyme disease who developed brief periods of arthritis $(n=4)$ and prolonged arthritis $(n=8)$, and in healthy controls $(n=23)$. In patients with prolonged arthritis, IgA Id 16/6 expression increased significantly during the first and third year $(p<0 \cdot 05)$, whereas there was a significant reduction ( $p<0.05$ ) in expression of IgM Id 16/6 with time. There was a significant difference between the increase and decrease in expression of IgA and IgM Id 16/6 respectively ( $p<0 \cdot 05)$. In those patients with brief arthritis, Id 16/6 expression on all isotypes tended to reduce.

subjects, but the control patients with SLE had increased expression of IgA PR4 (1.7(0.4); $\mathrm{p}<0.05)$ compared with healthy subjects.

COEXPRESSION OF IDS

Seven patients with Lyme disease had simultaneously increased expression of Ids $16 / 6$ and BEG2. Only one patient with prolonged arthritis had no expression on any of the isotypes.

\section{Case report}

A 58 year old man had erythema migrans followed by several brief episodes of arthritis affecting his wrists, knees, or interphalangeal joints. During the third year of illness he developed chronic arthritis of the right shoulder and hip, which was treated successfully with antibiotics during the fifth year of illness. IgM Id 16/6 expression was greatest during the first year of illness; it decreased rapidly and increased before a flare of chronic arthritis in the second year and again during a period of arthritis in the fifth year (fig 3). IgG Id 16/6 expression was greatest during the initial three years of illness. In contrast, IgA Id 16/6 expression increased during the initial episode of arthritis and again during the fifth year. No change in IgA Id 16/6 expression was detected during a flare of arthritis in the second year of illness. IgM Id $16 / 6$ levels correlated with total and $B$ burgdorferi specific IgM levels, but the amounts of IgG and IgA Id 16/6 did not correlate with their respective total or specific $B$ burgdorferi immunoglobulin levels. Id 16/6 expression on 

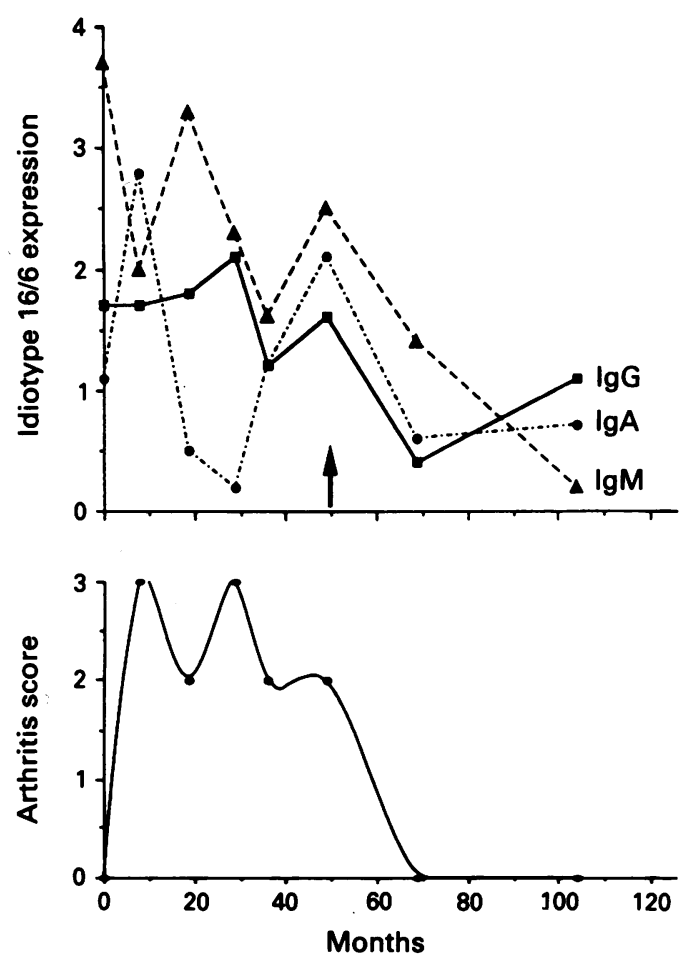

Figure 3 Serum idiotype (Id) 16/6 expression and arthritis score in a 58 year old man with chronic Lyme arthritis. IgM Id 16/6 expression $(\mathbf{\Delta}--\mathbf{\Delta})$ reduced from initially increased values on presentation with erythema migrans. IgG Id 16/6 expression (-) increased to a peak at 30 months of disease and then decreased to those of the healthy controls. IgA Id 16/6 expression (O. - . - ) peaked at 10 and 50 months, before decreasing to those of the healthy controls. Antibiotic treatment, indicated by the arrow, was associated with a simultaneous decrease in Id 16/6 expression on all isotypes.

all isotypes decreased simultaneously after treatment with antibiotics.

Similar findings were also found in the other seven patients investigated, although this patient was one of the more extensively investigated and had one of the longer follow up times.

\section{Discussion}

Data are presented that characterise the expression of public Ids in a cohort of patients with Lyme disease who developed varying degrees of arthritis, and this offers a unique opportunity to observe the humoral response to $B$ burgdorferi in patients not treated with antibiotics.

In Lyme disease a significant increase in the expression of serum IgM or IgG public Ids $16 / 6$ and BEG2 was shown and positive levels detected (greater than two SD above the mean for healthy control subjects) in half the patients investigated at some stage of illness. In contrast, IgA Id 16/6 expression was increased significantly only during episodes of arthritis and positive levels were detected in three of the eight patients with prolonged arthritis. IgA Id $16 / 6$ expression was also related to the severity of arthritis, but not the acute phase response, whereas IgM and IgG expression were not. Interestingly, IgM and IgG Id 16/6 expression correlated with their respective total immunoglobulin concentrations and, for $\operatorname{Ig} M$, to the level of IgM antibodies to $B$ burgdorferi, whereas similar findings were not found with IgA antibodies. Id $16 / 6$ bearing antibodies bind to the $B$ burgdorferi antigen, as was subsequently confirmed using $B$ burgdorferi sonicate in a capture ELISA. These data indicate that the IgM and IgG production is probably the major response against $B$ burgdorferi and perhaps IgA Id 16/6 expression is involved with more subtle factors relating to the pathogenesis of arthritis; perhaps associated with specific antibodies to $B$ burgdorferi, for example, against the outer surface protein A.

Sequential antibody studies showed that IgM and IgG Id 16/6 expression tended to decrease during prolonged illness, whereas IgA Id $16 / 6$ expression tended to increase. Furthermore, the difference between $\operatorname{IgM}$ and IgA expression was significant, which may indicate that isotype switching is occurring. In this respect it is pertinent that the humoral response against outer surface protein $\mathrm{A}$ in Lyme arthritis occurs late in the disease ${ }^{11}$ and in the patients reported here total IgA levels increased as the disease progressed. No evidence was found to suggest an association between the production of aCL antibodies and arthritis, indicating that the Id 16/6 bearing antibodies do not also have cardiolipin specificity. Comparable findings were observed in the patient reported, though the effects of antibiotic treatment seemed to correct these changes, giving further weight to the data indicating that Id $16 / 6$ is expressed on antibodies to $B$ burgdorferi. These changes were not apparent if the illness was brief, though the patients were not investigated for the same period of time.

Restriction in the expression of Id $16 / 6$ was also observed. Simultaneous expression of Id $16 / 6$ on all isotypes was never found and only one patient had increased expression of this idiotype on each isotype at different disease stages. Restriction was also found when Id PR4 was examined, as this was never expressed in Lyme disease; however, Ids 16/6 and BEG2 seem to be associated with a similar repertoire of antibodies to $B$ burgdorferi as seven patients expressed Id 16/6 simultaneously with Id BEG2. These Ids are not associated with the same $\mathrm{V}$ gene family, however; Id 16/6 and Id BEG2 are $\mathrm{V}_{\mathrm{H}} 3$ and $\mathrm{V}_{\mathrm{H}} 4$ associated respectively. By using Ids $16 / 6$ and BEG2 as markers of $V_{H}$ gene usage, an impression of the complexity of the humoral response to the $B$ burgdorferi bacterium can be seen. It is evident that the response is far from static as these Ids were not expressed continuously, but as a seemingly well orchestrated response with Ids appearing on different isotypes at different times. It is interesting that there is a similar expression of Ids $16 / 6$ and BEG2 in the patients with SLE studied, but with the important exception that Id PR4 rather than Id 16/6 was expressed on IgA. Perhaps these subtle Id fluctuations have clinical associations.

So does Id $16 / 6$ play a part in the pathogenesis of the disease? These data suggest that it does. It may simply be a marker of infection related antibodies or it may be a marker of a 
component of an idiotype network in which a cascade of interrelating antibodies is generated, any one of which may be pathogenic. ${ }^{12}$ For example, IgA bearing 16/6 may be antibody 3 (anti-Ab2) in a parallel set of Id $16 / 6$ positive and DNA binding negative autoantibodies, ${ }^{13}$ which may have antigen binding specificity to the $B$ burgdorferi antigen due to the presence of an internal image of the $B$ burgdorferi antigen occurring at the $\mathrm{V}$ region of antibody 2 (antiAbl - that is, the $B$ burgdorferi antibody). ${ }^{14}$ After processing the $16 / 6$ idiotope may be seen by $T$ cells, which, in the presence of certain HLA class II gene products (DR4, for example), cause them to become autoreactive and arthritogenic. ${ }^{15}$ Subsequent B cell activation may follow, which could result in pertubation of the antibody response.

In summary, these data indicate restriction in the expression of some public idiotypes in Lyme disease and a possible association between IgA antibodies bearing Id 16/6 and the development of arthritis. The associations with infection shown here further strengthen the suggestion that the main reason for the conservation of the public idiotypes is not to form part of an autoantibody response, but to help protect the species against environmental pathogens.

The authors thank Dr R S Schwartz for critical comment and for allowing us to use idiotype reagents prepared in his for allowing us to use idiotype reagents prepared in his globulin levels and for reviewing the manuscript, Dr L Tucker globulin levels and for reviewing the manuscript, Dr L Tucker for developing the Id 16/6 ELISA protocol, Dr A Puccetti for
helpful advice while carrying out this investigation, Ambrin Dar for technical assistance, and Professor I M Roitt and Mrs A Alavi for constructive criticism of the manuscript. JSA was Fulbright Scholar and thanks the Fulbright Commission an the Peel Medical Research Trust for financial assistance. RAW was supported by the Wellcome Foundation and the Emily L Rossignol Fund AAL was the recipient of a fellowship in basic sciences from the Canadian Arthritis Society and is a Sandos scholar in medicine. ACS Was suppo service grants AR-20358 and AR-40576. The anti-PR4 reagen was kindly donated by $\mathrm{Dr}$ W Williams.
1 Steere A C. Lyme disease. $N$ Engl $\mathcal{f}$ Med 1989; 321: 586-96.

2 Grodzicki R L, Steere A C. Comparison of immunoblotting and indirect enzyme-linked immunosorbent assay using different antigen preparations for diagnosing early Lyme different antigen preparations for diagno 7 Infect Dis 1988; 157: 790-7.

3 Mackworth-Young C G, Harris E N, Steere A C, et al. Anticardiolipin antibodies in Lyme disease. Arthritis Anticardiolipin antibodies

4 Shoenfeld Y, Isenberg D A, Rauch J, Madaio M P, Stolla B D, Schwartz R S. Idiotypic cross-reactions of monoclonal human lupus autoantibodies. $\mathcal{f} \operatorname{Exp} M e d$ 1983; 158: 718-30.

5 Williams W, Zumla A, Behrens R, et al. Studies of a common idiotype PR4 in autoimmune rheumatic disease. Arthritis Rheum 1988; 31: 1097-104.

6 Watts R A, Ravirajan C T, Staines N A, Isenberg D A. A human fetal monoclonal DNA-bínding antibody shares idiotypes with fetal and adult murine monoclonal DNAidiotypes with fetal and adult murine monoclonal
binding antibodies. Immunology 1990; 69: 348-54.

7 Chen P P, Liu M R, Sinha S, Carson D A. A 16/6 idiotypepositive anti-DNA antibody is encoded by a conserved $\mathrm{V}_{\mathrm{H}}$ gene with no somatic mutation. Arthritis Rheum 1988; 31 1429-31.

8 Isenberg D A, Collins C. Detection of cross-reactive antiDNA antibody idiotypes on renal tissue bound immunoglobulins from lupus patients. $\mathcal{f}$ Clin Invest 1985; 67: 287-94.

9 Beradi V P, Weeks K E, Steere A C. Serodiagnosis of early Lyme disease: analysis of $\operatorname{IgM}$ and IgG antibody responses by using an antibody-capture enzyme immunoresponses by using an antibody-captu
assay. $\mathcal{F}$ Infect Dis 1988; 158: 754-60.

10 Long A A, Ginsberg J S, Brill-Edwards P, et al. The relationship of antiphospholipid antibodies to thromboembolic disease in systemic lupus erthematosus: a cross sectional study. Thromb Haemost 1991; 66: $520-4$.

11 Kalish R, Leong J, Steere A C. Delay in the immune response to outer-surface proteins (Osp) $A$ and $B$ of Borrelia burgdorferi: correlation with arthritis and treatment failure in susceptible individuals. Arthritis Rheum. 1991; 34: S43.

12 Watts R A, Isenberg D A. Idiotypes and anti-idiotypes: what are they trying to tell us? Ann Rheum Dis 1988; 47: 705-7

13 Naparstek Y, Mackworth-Young C, Breitman L, Schwart $R$. Sequential anti-idiotypes define reciprocal idiotopes on the same anti-DNA antibody. Clin Immun Immunopatho 1989; 50: S106-16.

14 Puccetti A, Koizumi T, Migliorini P, André-Schwartz J, Barrett K J, Schwartz R S. An immunoglobulin light chain from a lupus-prone mouse induces autoantibodies in normal mice. $\mathcal{F} \operatorname{Exp} M$ Med 1990; 171: 1919-30.

15 Van-Eden W, Holoshitz J, Nevo Z, Frankel A, Klajman A Cohen I R. Arthritis induced by a T-lymphocyte clone that responds to mycobacterium tuberculosis and to cartilage proteoglycan. Proc Natl Acad Sci USA 1985; 82: 5117-20. 